\title{
Relative importance of heritable characteristics and lifestyle in the development of maternal obesity
}

\author{
Helen E Harris, George T H Ellison, Sarah Clement
}

\begin{abstract}
Study objective-To assess the relative importance of heritable characteristics and lifestyle in the development of "maternal obesity" after pregnancy.

Setting-South east London, in the homes of mothers who had delivered their babies at either Guy's, Lewisham or St Thomas's hospitals.

Participants-Seventy four mothers of low antenatal risk who had been enrolled in the Antenatal Care (ANC) Project (a previous trial of antenatal care) during the first trimester of pregnancy, and who had subsequently been followed up 2.5 years after delivery.

Design-Information on parental obesity, psychosocial and sociodemographic factors as well as lifestyle, was gathered during a semi-structured interview at each mother's home. Additional anthropometric and psychosocial data were taken from the existing ANC Project database. These data were used to assess the relative importance of heritable characteristics and lifestyle on changes in maternal body weight from the beginning of pregnancy to the follow up interview.
\end{abstract}

Main results-After adjusting for the effects of potential confounders and known risk factors for maternal obesity, women who selected larger silhouettes to represent their biological mothers were significantly more likely to have higher long term weight gains than those who selected thinner maternal silhouettes $(r=$ $0.083, p=0.004)$. Women who were less satisfied with their bodies postpartum had significantly greater long term weight gains than those women who displayed no increase in dissatisfaction with their bodies after pregnancy $(r=0.067, p=0.010)$. Conclusions-A heritable predisposition to gain weight together with changing attitudes to body size, both had an independent role in the development of maternal body weight after pregnancy. Differences in each woman's heritable predisposition to gain weight and any changes in body image that occur after pregnancy might explain why some women gain weight in association with pregnancy.

(F Epidemiol Community Health 1999;53:66-74)

The prevalence of female obesity (BMI>30) has increased gradually during the past 50 years. ${ }^{12}$ Even over the past decade, the overall prevalence of obesity in the UK has risen from $8 \%$ in 1980 to $12 \%$ in $1986 / 87 .{ }^{1}$ Similarly in the US, the NHANES-II data (1976-1980) show that more than one in four $(26 \%)$ American adults are overweight (BMI $>27.3$ for women and $\mathrm{BMI}>27.8$ for men). ${ }^{3}$ A comparison with earlier weight surveys shows that the incidence of obesity in America is increasing, with more women than men being affected. ${ }^{3}$

It has also become increasingly clear that obesity has a substantial adverse impact on health and well being ${ }^{14-6}$ : obesity is associated with a variety of serious illnesses and risk factors for disease, ${ }^{16}$ and long term obesity can have profound physiological effects, being associated with hypertension and impaired glucose tolerance, as well as conditions such as coronary heart disease, gall bladder disease, stroke, cancer, and diabetes. ${ }^{7}$ Not only does obesity aggravate the onset and progression of a variety of illnesses, but it also shortens life and reduces its quality ${ }^{6}$ because many obese people experience social discrimination and psychological distress as a direct consequence of their obesity. ${ }^{6}$ It is these health risks, along with the increasing prevalence of obesity within the UK, that led the British government in 1992 to identify "the reduction of obesity" as one of the main targets for health improvement in their white paper "Health of the Nation". 8 Six years later on, the growing prevalence of obesity has been highlighted as a "crucial factor" in the development of heart disease and stroke, one of four "priority areas" in the 1998 green paper "Our Healthier Nation". ."

The existence of residual energy stores after pregnancy has stimulated interest from a number of researchers and clinicians who presume that pregnant women ought to return to their pre-pregnant weight after pregnancy, ${ }^{10}$ and suspect that excessive fat deposition and/or energetic adaptations during pregnancy might cause an increase in the prevalence of obesity with parity. ${ }^{11-13}$ As early as 1862 , Gassner (cited by Stander and Pastore $^{14}$ ) recognised that pregnant women tend to gain more weight than that required for the products of conception. In 1942, Waters was able to demonstrate that a large proportion of this additional weight was not lost during the puerperium, ${ }^{15}$ and by 1949 , Sheldon argued that it was "a matter of common observation that women may... develop a severe obesity after having a baby". ${ }^{16}$ Undoubtedly, the view that pregnancy can lead to excessive weight gain has been widely held for some time, ${ }^{17}$ and in 1978 Bray included 
pregnancy as one of four potential endocrinological causes in his aetiological classification of obesity. ${ }^{19}$

The impact of pregnancy on maternal body weight is known to be associated with a number of sociodemographic, anthropometric, and obstetric factors. ${ }^{20-24}$ However, the importance of gestational weight gain as an independent risk factor for long term weight gain ${ }^{23} 25-30$ suggests that pregnancy is primarily associated with a persistent increase in body weight simply because it is a period of positive energy balance during which some women gain excessive weight. ${ }^{23}$ Likewise, the strong association between long term weight gain and prepregnant body mass index (BMI) 23283132 suggests that a pre-existing predisposition to obesity increases the risk of long term weight gain after pregnancy. Yet, with the exception of Cederlöf and Kaij's study of parous and nulliparous monozygotic twins, ${ }^{11}$ no studies have yet investigated the influence of heritable characteristics (either genetic or social) on the development of postpartum body weight.

Changes in the postpartum psychosocial environment might also impact on maternal energy balance by influencing energy intake and energy expenditure as well as psychological well being and attitudes to weight gain. However, there have been few studies that investigated the effects of lifestyle changes on pregnancy related weight gain, ${ }^{31} 3334$ and those that have, often generated conflicting results. For example, Schauberger et $a l^{11}$ showed that mothers who resumed work within two weeks of delivery retained significantly less weight at six months postpartum compared with mothers who returned to work at some later stage. However, this association between delayed re-employment and greater long term weight gain was not the result of significant differences in activity, ${ }^{31}$ and Öhlin and Rössner found no association between either employment or activity and long term maternal weight gain. ${ }^{33}$ It therefore remains unclear whether heritable factors or changes in lifestyle explain any of the variation in long term weight gains experienced by different women after pregnancy. The aim of this study was to assess the relative importance of heritable characteristics and lifestyle in the development of maternal obesity.

\section{Methods}

\section{SAMPLE}

The sample was drawn from mothers of low antenatal risk who were enrolled in the Antenatal Care (ANC) Project (a randomised controlled trial comparing two schedules of antenatal visits), ${ }^{35}$ and who were followed up in the ANC Project follow up study by postal questionnaire approximately 2.5 years after delivery. Women were asked on their follow up questionnaire whether they would be interested in participating in a study looking at the relation between pregnancy, motherhood, and long term maternal weight gain. Any mothers who indicated that they were interested in participating were sent full details of the present study along with a letter to obtain informed consent. Women were eligible for inclusion in the study if: (a) they had been weighed during the first trimester of pregnancy (to provide a reliable estimate of their prepregnant weight), ${ }^{36}$ and (b) they had not become pregnant since the birth of the child they carried during the ANC Project (to exclude any effect of subsequent pregnancies on their body weight). ${ }^{37}$ Seventy six mothers were eligible for inclusion in the study, although two cases were excluded because of missing data. Table 1 summarises the anthropometric and sociodemographic characteristics of these 74 woman. The 74 women included in this study did not differ significantly from the other mothers in the ANC Project cohort in terms of their body weight at booking $(t=0.76, \mathrm{p}=0.45)$, parity $(\mathrm{U}=94290, \mathrm{p}=0.44)$, or the age at which they completed their full time education $\left(\chi^{2}=1.48\right.$, $\mathrm{p}=0.48$ ), yet they were significantly more likely to own their homes $\left(\chi^{2}=12.83, \mathrm{p}<\right.$ $0.001)$, live with their partners $\left(\chi^{2}=5.12, \mathrm{p}=\right.$ 0.03 ), and were 2.3 years older than the other mothers in the ANC Project cohort $(t=4.03, \mathrm{p}$ $<0.001)$. This comparison suggests that the mothers in the present study were somewhat unrepresentative of those in the ANC Project cohort as a whole, being slightly older, wealthier women, more of whom were living with a partner. However, the sample did not differ in those key anthropometric (booking weight) and reproductive (parity) characteristics that are known to be associated with a differential risk of maternal obesity in women from south east England. ${ }^{23} 24$

\section{DESIGN}

Information on parental obesity and psychosocial variables, as well as on lifestyle changes and sociodemographic factors, was gathered during a semi-structured interview conducted at each mother's home (see table 2), using an interview schedule designed to give the maximum opportunity for complete and accurate communication of views between the mother and the researcher. ${ }^{39}$ Additional data were taken from the original ANC Project database, which contained information from maternity case notes and maternal responses to postal questionnaires that were completed at 34 weeks gestation, 6 weeks postpartum, and 2.5 years after delivery.

Approval for the study was obtained from the ethics committees of Guy's, Lewisham, and St Thomas's hospitals, as well as from the University of Greenwich's Ethical Committee.

\section{MEASURES}

To control for known obstetric and sociodemographic risk factors for pregnancy related weight gain, information on maternal age, marital status, housing tenure, and parity were abstracted from the ANC Project database. To control for the association between prepregnant BMI and long term weight gain,,$^{23} 283132$ weight and height measurements that had been recorded during the first trimester of pregnancy were used to provide an estimate of prepregnant BMI. ${ }^{36}$ Maternal reports of gestational weight gain and current smoking 
Table 1 Sociodemographic and anthropometric characteristics of the women in the sample $(n=74)$

\begin{tabular}{|c|c|}
\hline Characteristic & $\begin{array}{l}\text { Mean }(S E M)^{\dagger} \\
\text { or per cent }(n)\end{array}$ \\
\hline Maternal age (y) & $33.54(0.56)^{\dagger}$ \\
\hline Maternal height (m) & $1.64(0.01)^{\dagger}$ \\
\hline Maternal weight at first antenatal visit (kg) & $66.23(1.25)^{\dagger}$ \\
\hline Self reported gestational weight gain $(\mathrm{kg})$ & $12.93(0.67)^{\dagger}$ \\
\hline \multicolumn{2}{|l|}{ Parity at first antenatal visit } \\
\hline 0 & $37.8(28)$ \\
\hline 1 & $44.6(33)$ \\
\hline 2 & $12.2(9)$ \\
\hline 3 & $2.7(2)$ \\
\hline 4 & $1.4(1)$ \\
\hline 5 & $1.4(1)$ \\
\hline Smokers at first antenatal visit & $43.2(32)$ \\
\hline Currently married & $55.4(41)$ \\
\hline \multicolumn{2}{|l|}{ Age when finished full time education } \\
\hline 16 or $<$ years & $29.7(22)$ \\
\hline $17-18$ years & $31.1(23)$ \\
\hline 19 or $>$ years & $39.2(29)$ \\
\hline \multicolumn{2}{|l|}{${ }^{\star}$ Current socioeconomic status } \\
\hline I & $18.9(14)$ \\
\hline II & $9.5(7)$ \\
\hline IIIN & $16.2(12)$ \\
\hline IIIM & $10.8(8)$ \\
\hline IV & $25.7(19)$ \\
\hline $\mathrm{V}$ & $13.5(10)$ \\
\hline $\mathrm{X}$ & $5.4(4)$ \\
\hline Own or buying their home & $64.9(48)$ \\
\hline
\end{tabular}

*According to the Registrar General's Classification of Occupations. ${ }^{38}$

behaviour were obtained during the semistructured interview, ${ }^{39}$ and by linking this information to earlier reports of smoking behaviour collected during the ANC Project it was possible to identify any mothers whose smoking habits had changed during their reproductive cycle. To control for the effect of aging related weight gain, the interval between the first antenatal visit and the follow up interview was included in the analyses of long term weight gain. Finally, the gestational age at which mothers had their first antenatal weight measurement was included in the analyses, to account for any effect of gestational age on maternal body weight recorded at the beginning of pregnancy. Measurements of body weight and height were taken at the time of the interview using the same set of scales and measuring tape (Scale: Soehnle 7306.00; Tape: Microtoise 04116 ), and the scales were

Table 2 Sociodemographic, anthropometric, obstetric, heritable, psychosocial, and lifestyle variables whose role in the development of maternal obesity was examined in this study

\begin{tabular}{|c|c|}
\hline Type of variable & Variable \\
\hline Sociodemographic & $\begin{array}{l}\text { Maternal age (y) } \\
\text { Marital status (married } v \text { single) } \\
\text { Housing tenure (owned/buying } v \text { renting/living rent free) } \\
\text { Interval from first antenatal visit to follow up interview (days) }\end{array}$ \\
\hline Anthropometric & $\begin{array}{l}\text { Body mass index at the first antenatal visit }\left(\mathrm{kg} / \mathrm{m}^{2}\right) \\
\text { Self reported gestational weight gain }(\mathrm{kg})\end{array}$ \\
\hline Obstetric & $\begin{array}{l}\text { Parity (n) } \\
\text { Gestational age at the first antenatal visit (weeks) }\end{array}$ \\
\hline Heritable & Parental obesity $(1-9)^{\star}$ \\
\hline Psychosocial & $\begin{array}{l}\text { Parenting stress }(101-505)^{\star} \\
\text { Social support network size }(0-9)^{\star} \\
\text { Social support satisfaction }(1-6)^{\star} \\
\text { Depression }(0-30)^{\star} \\
\text { Increased drive for thinness postpartum }(\mathrm{Yes} / \mathrm{No}) \\
\text { Increased dissatisfaction with the body postpartum }(\mathrm{Yes} / \mathrm{No})\end{array}$ \\
\hline Behavioural & $\begin{array}{l}\text { Increased access to food postpartum (Yes/No) } \\
\text { Postpartum dieting (Yes/No) } \\
\text { Dietary restraint }(1-5)^{\star} \\
\text { Increased energy intake postpartum (Yes/No) } \\
\text { Decreased exercise postpartum (Yes/No) } \\
\text { Smoking status (never smoked, quit/reduced smoking, started smoking, } \\
\text { continual smoker) } \\
\text { Duration of lactation (days) }\end{array}$ \\
\hline
\end{tabular}

$\star$ Range of possible scores. calibrated professionally to within $200 \mathrm{~g}$ using weights traceable to National Standards (Austin White Ltd, Northampton). Any long term changes in body weight that accompanied pregnancy were calculated as: current weight (measured at the time of the interview) minus weight measured during the first trimester of pregnancy. Information concerning parental obesity, psychosocial factors, and lifestyle changes was gathered during the semistructured interview and these variables are described in detail below:

"Heritable" predisposition to gain weight

"Heritable" predisposition to gain weight was assessed using the Silhouette Technique. ${ }^{40}$ This instrument asked subjects to score the degree of obesity in their parents using a series of nine silhouette drawings showing bodies of increasing obesity, ranging from very thin to very obese (numbered in order from 1 to 9 ). The silhouette scoring technique has been validated by correlations with BMI as offspring's selected silhouettes of their mothers have been shown to correlate well with measured maternal BMI $(r$ $=0.74){ }^{40}$

\section{Parenting stress}

The stress of parenthood was assessed using the 101 item Parenting Stress Index (PSI), ${ }^{41}$ which was administered during the ANC Project follow up study. The PSI has proven reliability and validity as a measure of the stresses associated with parenting. ${ }^{41}$

\section{Social support after pregnancy}

Social support was assessed using the short form of the Social Support Questionnaire (SSQ6). ${ }^{42}$ The SSQ6 was developed by Sarason $e t a l^{42}$ and is a condensed version of the original 27 item social support questionnaire. ${ }^{43}$ The SSQ6, like its predecessor, yields a structural measure of the number of supportive relationships available to an individual, and also provides an indication of satisfaction with the support available. SSQ6 has high internal consistency for both the number and satisfaction subscales, and high test-retest reliability. ${ }^{44}$

Depression

Maternal depression was assessed using the Edinburgh Postnatal Depression Scale (EPDS) ${ }^{45}$ which was administered by postal questionnaire during the ANC Project follow up study. The EPDS is a screening tool for detecting postnatal depression that has been validated for use outside the immediate postnatal period. ${ }^{46}$ The EPDS represents a valid and reliable measure of depression that has satisfactory sensitivity and specificity. ${ }^{45}$

\section{Changes in drive for thinness}

Changes in attitudes to weight gain were assessed using the drive for thinness subscale of the Eating Disorder Inventory (EDI-DT). ${ }^{47}$ This scale contains seven questions that assess "concern with dieting, preoccupation with weight, and entrenchment in an extreme pursuit of thinness". This scale has established internal consistency, as well as convergent and 
Table 3 Sociodemographic, anthropometric, obstetric, heritable, psychosocial, and behavioural characteristics of the 37 mothers with long term weight gains greater than 0.4 $\mathrm{kg}$, compared with those of the 37 mothers with long term weight gains less than $0.4 \mathrm{~kg}$

\begin{tabular}{|c|c|c|}
\hline Maternal characteristic & $\begin{array}{l}\text { Women with long } \\
\text { term weight gains } \\
<0.4 \mathrm{~kg}\end{array}$ & $\begin{array}{l}\text { Women with long } \\
\text { term weight gains } \\
>0.4 \mathrm{~kg}\end{array}$ \\
\hline \multicolumn{3}{|l|}{ Sociodemographic } \\
\hline Maternal age (y) & $33.4(0.8)^{\star}$ & $33.7(0.8)$ \\
\hline Married (\%) & 54.1 & 56.8 \\
\hline Own/buying home (\%) & 67.2 & 62.2 \\
\hline Duration of follow up (days) & $1141.2(20.0)$ & $1181.8(20.6)$ \\
\hline \multicolumn{3}{|l|}{ Anthropometric } \\
\hline $\mathrm{BMI}$ at first antenatal visit $\left(\mathrm{kg} / \mathrm{m}^{2}\right)$ & $25.0(0.6)$ & $24.2(0.7)$ \\
\hline \multirow{2}{*}{\multicolumn{3}{|c|}{ 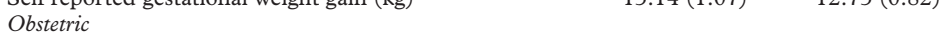 }} \\
\hline & & \\
\hline Parity at first antenatal visit (n) & $0.9(0.1)$ & $0.9(0.2)$ \\
\hline Gestational age at first antenatal visit (weeks) & $11.32(0.22)$ & $10.73(0.27)$ \\
\hline \multicolumn{3}{|l|}{ Heritable } \\
\hline Obesity of biological mother (1-9) & $4.67(0.27)$ & $5.14(0.28)$ \\
\hline Obesity of biological father (1-9) & $4.56(0.32)$ & $4.63(0.32)$ \\
\hline \multicolumn{3}{|l|}{ Psychosocial } \\
\hline Parenting stress $(101-505)$ & $221.8(5.9)$ & $223.2(6.5)$ \\
\hline Social support network size (1-9) & $1.94(0.22)$ & $1.51(0.10)$ \\
\hline Social support satisfaction (1-6) & $5.32(0.09)$ & $5.28(0.11)$ \\
\hline Depression $(0-30)$ & $6.62(0.92)$ & $4.97(0.78)$ \\
\hline Increased drive for thinness postpartum (\%) & 40.5 & 48.6 \\
\hline \multicolumn{3}{|l|}{ Behavioural } \\
\hline Increased access to food postpartum (\%) & 70.3 & 51.4 \\
\hline Actively dieted postpartum (\%) & 51.4 & 51.4 \\
\hline Dietary restraint postpartum $(1-5)$ & $2.48(0.16)$ & $2.47(0.16)$ \\
\hline Increased energy intake postpartum (\%) & 35.1 & 18.9 \\
\hline Decreased exercise postpartum (\%) & 56.8 & 40.5 \\
\hline \multicolumn{3}{|l|}{ Smoking status (\%) } \\
\hline Never smoked & 43.2 & 64.9 \\
\hline Started smoking & 2.7 & 2.7 \\
\hline Quit or reduced smoking & 35.1 & 35.1 \\
\hline Continual smoker & 18.9 & 18.9 \\
\hline Duration of lactation (weeks) & $24.5(5.2)$ & $32.5(6.5)$ \\
\hline
\end{tabular}

«Mean (SEM). †p=0.002.

discriminant validity. ${ }^{47}$ This instrument was administered twice: once retrospectively, when women were asked to recall their feelings before they were pregnant, and again to assess their current feelings at the time of the interview. Change in drive for thinness was calculated as the difference in drive for thinness scores before and after pregnancy.

Changes in body image

Changes in body image were assessed using a self directed application of the Silhouette

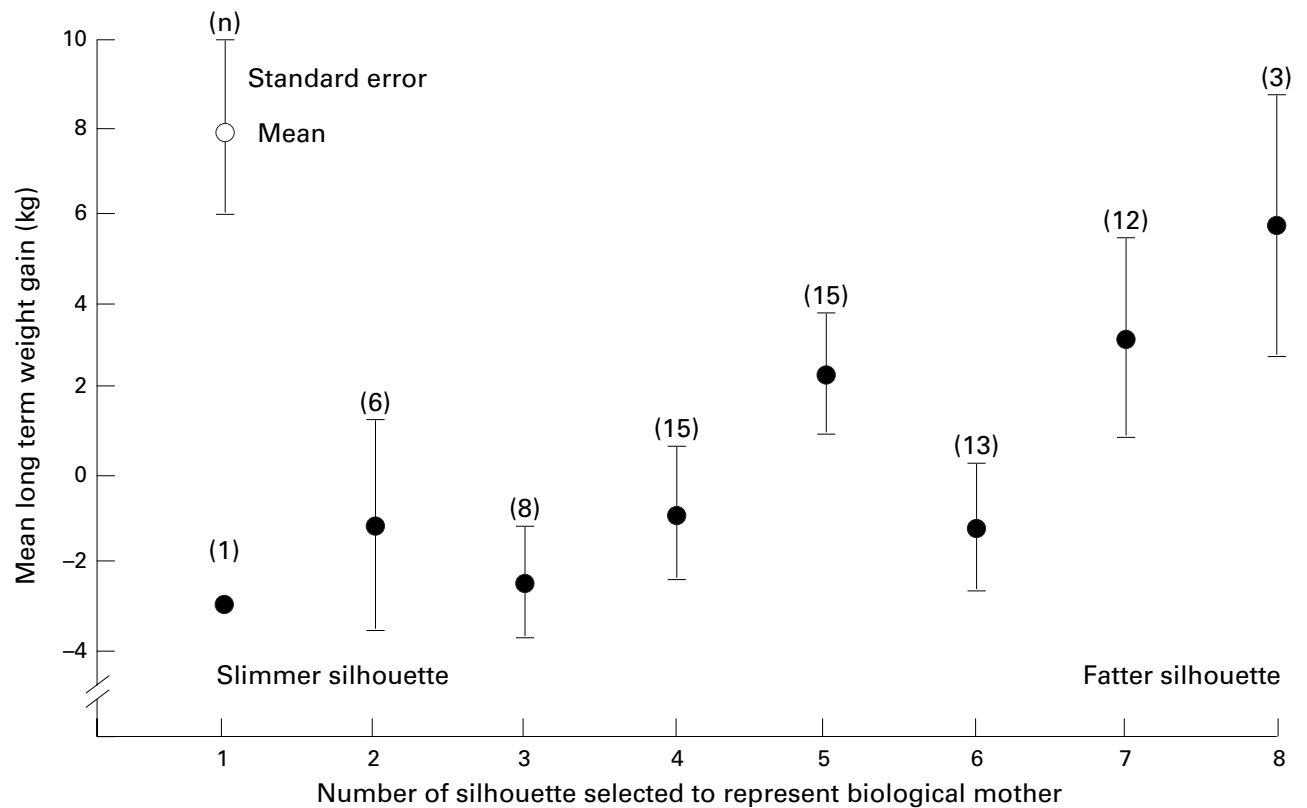

Figure 1 Mean long term weight gains of the 74 women in the sample according to the number of silhouette selected to represent thier biological mothers.
Technique. ${ }^{40}$ Here a series of silhouette drawings, showing bodies of increasing obesity, ranging from very thin to very obese (numbered in order from 1 to 9), were presented to the respondents on a flashcard. The respondents were then invited to select the number of the image which: (a) "looks most like you just before you became pregnant", (b) "best represents what you ideally wanted to look like just before you became pregnant", (c) "looks most like you now", and (d) "best represents what you ideally want to look like now". The discrepancy in size between silhouettes selected to represent actual body size and ideal body size provided an indication of dissatisfaction with body size. Change in body dissatisfaction was calculated as the difference between body dissatisfaction before pregnancy and body dissatisfaction after pregnancy.

\section{Changes in access to food after pregnancy}

Changes in access to food were assessed using maternal responses to the statement: "After my child was born, I had greater access to food throughout more of the day than I did before I became pregnant". Mothers responded to this statement by selecting the most appropriate answer from five possible responses ranging from "agree strongly" to "disagree strongly".

\section{Postpartum dieting}

Postpartum dieting was assessed by recording the dichotomous response to the question: "Since the birth of your child, have you actively tried to lose weight?".

\section{Dietary restraint}

The degree of restraint that mothers exerted over their eating during the postpartum period was assessed using the Restraint Scale of the Dutch Eating Behaviour Questionnaire (DEBQ) ${ }^{48}$ This scale is directed specifically towards restricting food intake on grounds of 
Table 4 Cross tabulated associations between parental obesity and lifestyle variables, along with potential confounders and risk factors for long term weight gain

\begin{tabular}{|c|c|c|c|c|c|c|c|c|c|c|c|c|c|c|c|}
\hline \multicolumn{2}{|c|}{ Variable } & 1 & 2 & 3 & 4 & 5 & 6 & 7 & 8 & 9 & 10 & 11 & 12 & 13 & 14 \\
\hline 1 & Maternal age & $\mathrm{X}$ & $<.01$ & .28 & .89 & .62 & .03 & .68 & .91 & .71 & .01 & .23 & .92 & .96 & .98 \\
\hline 2 & Marital status & & $\mathrm{x}$ & .16 & .59 & .77 & .73 & .86 & .21 & .17 & .55 & .47 & .06 & .65 & .00 \\
\hline 3 & Duration of follow up & & & $\mathrm{X}$ & .86 & .21 & .74 & .18 & .55 & .48 & .63 & .53 & .69 & .55 & .85 \\
\hline 4 & Prepregnant body mass index & & & & $\mathrm{X}$ & .18 & .71 & .82 & .48 & .06 & .57 & .43 & .72 & .20 & .20 \\
\hline 5 & Self reported gestational weight gain & & & & & $\mathrm{X}$ & .69 & .93 & .90 & .31 & .18 & .12 & .32 & .51 & .30 \\
\hline 6 & Parity at first antenatal visit & & & & & & $\mathrm{x}$ & .88 & .68 & .72 & .23 & .13 & .71 & .15 & .23 \\
\hline 7 & Gestational age at first antenatal visit & & & & & & & $\mathrm{X}$ & .91 & .12 & .27 & .29 & .98 & .17 & .57 \\
\hline 8 & Parental obesity & & & & & & & & $\mathrm{X}$ & .55 & .44 & .76 & .62 & .45 & .59 \\
\hline 9 & Social support network size & & & & & & & & & $\mathrm{X}$ & .50 & .26 & .96 & .84 & .16 \\
\hline 10 & Change of body image & & & & & & & & & & $\mathrm{X}$ & .16 & .03 & .00 & .70 \\
\hline 11 & Change in access to food & & & & & & & & & & & $\mathrm{X}$ & .79 & .16 & .03 \\
\hline 12 & Change in energy intake & & & & & & & & & & & & $\mathrm{X}$ & .01 & .66 \\
\hline 13 & Change in activity & & & & & & & & & & & & & $\mathrm{X}$ & .07 \\
\hline 14 & Smoking status & & & & & & & & & & & & & & $\mathrm{X}$ \\
\hline
\end{tabular}

Data presented as probability p values.

weight control, and has established reliability and validity. ${ }^{48}$

Changes in energy intake after pregnancy Changes in energy intake were assessed using maternal responses to the statement: "I eat more now than I did before I was pregnant". Again, mothers responded to this statement by selecting the most appropriate answer from five possible responses ranging from "agree strongly" to "disagree strongly".

\section{Changes in activity after pregnancy}

Changes in activity were assessed using maternal responses to the statement: "I take less exercise than I did before I was pregnant". Once again, mothers responded to this statement by selecting the most appropriate answer from five possible responses ranging from "agree strongly" to "disagree strongly".

Table 5 The full ANCOVA model with long term maternal weight gain $(\mathrm{kg})$ as the dependant variable (Adjusted $r^{2}=0.266, d f=16$ and $73, F=2.63, p<0.01$ )

\begin{tabular}{|c|c|c|c|c|}
\hline Factors & $\begin{array}{l}\text { Adjusted long } \\
\text { term } \\
\text { maternal } \\
\text { weight gain } \\
(\mathrm{kg})\end{array}$ & $F$ & \multicolumn{2}{|l|}{$p$} \\
\hline Marital status & & 0.00 & \multicolumn{2}{|c|}{0.990} \\
\hline Married & 0.80 & & & \\
\hline Unmarried & 0.29 & & & \\
\hline Increased dissatisfaction with body & & 7.67 & \multicolumn{2}{|c|}{0.008} \\
\hline Yes & 2.77 & & & \\
\hline No & -1.60 & & & \\
\hline Increased access to food & & 1.52 & \multicolumn{2}{|c|}{0.223} \\
\hline Yes & 1.84 & & & \\
\hline No & -0.67 & & \multirow{2}{*}{\multicolumn{2}{|c|}{0.117}} \\
\hline Increased energy intake & & 2.54 & & \\
\hline Yes & 2.29 & & & \\
\hline No & -0.30 & & & \\
\hline Decreased activity & & 0.64 & \multicolumn{2}{|c|}{0.428} \\
\hline Yes & 0.90 & & & \\
\hline No & 0.24 & & \multirow{2}{*}{\multicolumn{2}{|c|}{0.581}} \\
\hline Smoking status & & 0.66 & & \\
\hline Non-smoker & 1.70 & & & \\
\hline Quit/reduced & -0.06 & & & \\
\hline Started & -0.02 & & & \\
\hline Continual & -1.87 & & & \\
\hline Covariates & $B$ & $\beta$ & SEM & $p$ \\
\hline Maternal age (y) & 0.023 & 0.018 & 0.178 & 0.896 \\
\hline Duration of follow up (days) & 0.005 & 0.100 & 0.005 & 0.358 \\
\hline Prepregnant body mass index $\left(\mathrm{kg} / \mathrm{m}^{2}\right)$ & -0.292 & -0.189 & 0.179 & 0.108 \\
\hline Self reported gestational weight gain $(\mathrm{kg})$ & -0.031 & -0.029 & 0.120 & 0.796 \\
\hline Parity (n) & -0.628 & -0.101 & 0.711 & 0.381 \\
\hline Gestational age at booking (weeks) & -0.605 & -0.151 & 0.462 & 0.196 \\
\hline Parental obesity (1-9) & 0.977 & 0.271 & 0.384 & 0.014 \\
\hline Social support $(0-9)$ & -0.680 & -0.118 & 0.698 & 0.334 \\
\hline
\end{tabular}

Duration of breast feeding

Information on the duration of breast feeding was obtained from the ANC Project database. Here mothers had been asked by postal questionnaire at 6 weeks postpartum and again at 2.5 years postpartum if they: (a) had ever breast fed their child, (b) were currently breast feeding, and, if appropriate (c) when breast feeding had stopped.

STATISTICAL ANALYSIS

Data were analysed using the Statistical Package for the Social Sciences (SPSS Inc, Chicago). All data are reported as mean (SEM) or as percentages. Relations between long term weight gain and between the variables under test were assessed using independent sample $t$ tests or Mann-Whitney U tests for dichotomous variables, one way analyses of variance (ANOVAs) or $\chi^{2}$ tests for categorical variables, and Pearson's correlation coefficients or Spearman's rank correlation coefficients for continuous variables. The independent associations between long term maternal weight gain and the variables under test were assessed using analyses of covariance (ANCOVAs) to control for a variety of potential confounders and other established risk factors for pregnancy related weight gain (see table 2). The form of the regression was assessed by examining a scattergram of the residuals (SPSS Inc, Chicago).

\section{Results}

The mothers in the sample were interviewed, on average, $2.63(0.04)$ years after the birth of their child. The mean long term weight gain in association with pregnancy was $0.50(0.71) \mathrm{kg}$ so that, overall, the 74 mothers in the sample were not significantly heavier after pregnancy than they were before $(95 \% \mathrm{CI}:-0.89,1.89)$. However, these long term weight gains were very variable, ranging from a weight loss of $13.6 \mathrm{~kg}$ to a weight gain of $17.7 \mathrm{~kg}$.

Table 3 shows the sociodemographic, anthropometric, obstetric, heritable, psychosocial, and behavioural characteristics of the 37 mothers with long term weight gains greater than $0.4 \mathrm{~kg}$ (the median long term weight gain), compared with the remaining 37 mothers who had long term weight gains less than $0.4 \mathrm{~kg}$. The only characteristic that was signifi- 
Table 6 The final ANCOVA model with the highest adjusted variance, with long term maternal weight gain $(\mathrm{kg})$ as the dependant variable (Adjusted $r^{2}=0.310, d f=8$ and 73 , $F=5.05, p<<0.001)$

\begin{tabular}{|c|c|c|c|c|}
\hline Factors & $\begin{array}{l}\text { Adjusted } \\
\text { long term } \\
\text { maternal } \\
\text { weight gain } \\
\text { (kg) }\end{array}$ & $F$ & & $p$ \\
\hline Increased dissatisfaction with the body & & 7.00 & & 0.010 \\
\hline Yes & 2.65 & & & \\
\hline No & -1.18 & & & \\
\hline Increased access to food & & 2.55 & & 0.115 \\
\hline Yes & 2.07 & & & \\
\hline No & -0.61 & & & \\
\hline Increased energy intake & & 3.23 & & 0.077 \\
\hline Yes & 2.64 & & & \\
\hline No & -0.26 & & & \\
\hline Covariates & $B$ & $\beta$ & SEM & $p$ \\
\hline Duration of follow up (days) & 0.005 & 0.109 & 0.005 & 0.286 \\
\hline Prepregnant body mass index $\left(\mathrm{kg} / \mathrm{m}^{2}\right)$ & -0.205 & -0.132 & 0.157 & 0.198 \\
\hline Gestational age at booking (weeks) & -0.469 & -0.117 & 0.418 & 0.266 \\
\hline Parental obesity (1-9) & 1.054 & 0.292 & 0.358 & 0.004 \\
\hline Social support (0-9) & -1.021 & -0.177 & 0.598 & 0.093 \\
\hline
\end{tabular}

cantly different between these two groups was increased dissatisfaction with body image. Mothers who gained more than $0.4 \mathrm{~kg}$ in association with their pregnancies were more likely to have increased dissatisfaction with their bodies $(62.2 \%)$ than those women with long term weight gains less than $0.4 \mathrm{~kg}(27.0 \%$; $\chi^{2}=9.24, p=0.002$ ).

Long term weight gain after pregnancy was significantly associated with maternal reports of their biological mother's size (that is, their child's grandmother), as assessed using the Silhouette Technique of Sørensen and Stunkard ${ }^{40}$ $(r=0.28, \mathrm{p}=0.030)$. Those mothers who selected higher numbered silhouettes (representing larger biological mothers) gained significantly more weight than those mothers who selected slimmer silhouettes to represent their biological mothers (see fig 1). However, long term weight gain was not significantly associated with the silhouettes selected to represent biological fathers $(r=0.05, \mathrm{p}=0.477)$.

Statistical associations between a heritable predisposition to obesity (as measured by parental obesity), pre-existing obesity (as measured by maternal nutritional status: BMI at the beginning of pregnancy), and each of the social, psychological and lifestyle changes that accompanied pregnancy and motherhood, have been summarised in table 4 . The significant associations between these characteristics and those directly related to energy balance (such as increased access to food, increased energy intake, smoking cessation, and reduced activity) demonstrate the potential impact of "heritable" and psychosocial factors on pregnancy related weight gain. Likewise, the associations between these factors and established sociodemographic risk factors for long term weight gain (maternal age, parity, marital status, aging during the period of follow up, and gestational weight gain), demonstrate the potential for confounding that might have been responsible for the relations observed between "heritable" characteristics, psychosocial factors, lifestyle changes, and long term weight gain. For example, table 4 shows that older mothers were significantly more likely to be married $(\mathrm{p}<0.001)$ and to be of higher parity ( $p=0.027$ ), but less likely to have increased levels of dissatisfaction with their bodies after pregnancy $(\mathrm{p}=0.006)$. Likewise, mothers who had increased levels of dissatisfaction with their bodies after pregnancy were significantly more likely to report eating more and taking less exercise postpartum $(\mathrm{p}=0.032$; $\mathrm{p}=0.001)$. There was a strong trend for self reports of social support to be associated with body mass index at the beginning of pregnancy, with smaller social support networks among leaner mothers $(p=0.059)$. Marital status was significantly associated with smoking status $(\mathrm{p}$ $=0.003$ ) such that married mothers were more likely to be non-smokers, whereas single mothers were more likely to have smoked throughout pregnancy and the postpartum period, and were therefore more likely to report quitting or reducing their level of smoking during pregnancy. Smoking was significantly associated with a reported decrease in access to food $(\mathrm{p}=$ 0.026), such that smoking throughout pregnancy and the postpartum period was associated with decreased access to food after pregnancy, whereas never smoking, quitting or reducing the level of smoking were associated with increased access to food after pregnancy. This might explain why there was also a strong trend for married women to report increasing their energy intake after pregnancy $(\mathrm{p}=$ 0.064 ), as they were less likely to smoke (see above). Reports of increased energy intake after pregnancy were significantly associated with reports of decreased activity postpartum ( $\mathrm{p}=$ 0.008).

To establish whether there were any associations between parental obesity, psychosocial changes, energetic behaviour, and long term weight gain that were independent of established risk factors for weight gain, an analysis of covariance was conducted to control for potential confounding. The variables included in the ANCOVA were chosen to provide an appropriate sample of those "heritable" characteristics (parental obesity), psychosocial factors (social support and dissatisfaction with body image), and lifestyle changes (increased access to food, increased energy intake, and decreased activity) that were most strongly related to long term weight gain. Additional variables were selected to control for potential confounding between these and established risk factors for long term weight gain (that is, marital status, maternal age, parity, nutritional status at the beginning of pregnancy, gestational weight gain, and changes in smoking status). Gestational age at which body weight was first recorded early in pregnancy and the duration of follow up between this initial weight measurement and that recorded at the postpartum interview were also included in the ANCOVA to account for any differences between mothers that might have influenced their estimated prepregnant weight or the amount of time over which subsequent weight gain might have occurred. ${ }^{24}$

A variety of maternal characteristics were associated with long term maternal weight gain and together these accounted for $26.6 \%$ of the adjusted variance in long term maternal weight 
gain (see table 5). To improve the predictive power of the ANCOVA model, those variables that explained the least amount of variance were removed one by one, in a backward, stepwise approach, until the model with the highest adjusted variance was obtained. Marital status $\left(r^{2}<0.001\right)$, maternal age $\left(r^{2}<0.001\right)$, self reported gestational weight gain $\left(r^{2}=0.001\right)$, decreased activity $\left(r^{2}=0.006\right)$, smoking status $\left(r^{2}=0.027\right)$, and parity $\left(r^{2}=0.008\right)$ were all removed from the original model. The final model contained eight variables that explained $31.0 \%$ of the adjusted variance in long term maternal weight gain (table 6). Of these variables, increased dissatisfaction with body image $\left(r^{2}=0.067, \mathrm{p}=0.010\right)$ and parental obesity $\left(r^{2}=0.083, \mathrm{p}=0.004\right)$ were both independently associated with long term changes in maternal body weight (see table 6). Mothers who felt more dissatisfied with their bodies after pregnancy had significantly greater long term weight gains. Likewise, those mothers who selected larger silhouettes to represent their biological mothers gained significantly more weight in association with pregnancy. Modest trends towards higher long term weight gains were also observed among women who (a) felt they ate more postpartum than they did before they were pregnant $(p=0.077)$, and (b) had smaller social support networks ( $p$ $=0.093)$.

\section{Discussion}

The results of this study suggest that a heritable predisposition to gain weight and changes in attitude towards body size might both have an independent role in the development of maternal body weight after pregnancy. After adjusting for the effects of potential confounders and known risk factors for maternal obesity, women who selected more obese silhouettes to represent their biological mothers were significantly more likely to have higher long term weight gains than those who selected less obese silhouettes to represent their biological mothers. This suggests that some component of heredity determines why some women gain more weight than others in association with pregnancy. A number of previous studies have shown that the familial resemblance of obesity has a genetic component that may be inherited, ${ }^{40}{ }^{49-51}$ with twin and adoption studies indicating that genes play a major part. ${ }^{49}$ However, it is also possible that offspring "inherit" lifestyles that predispose them to gain weight by adopting similar eating habits and exercise patterns to those of their parents. The absence of an association between long term maternal weight gain and the size of the biological father suggests that inherited maternal attitudes to body weight and weight gain, as well as postpartum lifestyle, might be the underlying cause of the association between the long term weight gain and maternal body size, rather than any genetic characteristic inherited from both parents. Nevertheless, it is likely that both processes have a part to play.

The ANCOVA models also showed that mothers who were more dissatisfied with their bodies postpartum had significantly greater
KEY POINTS

- In a contemporary sample of British mothers most women failed to display a net increase in body weight two and a half years after their pregnancy.

- A sizeable minority of women (17.6\%) had net long term weight gains of more than $5 \mathrm{~kg}$.

- Women with overweight or obese biological mothers were at increased risk of long term weight gain.

- Excess weight gain after pregnancy was associated with increased dissatisfaction with body size.

long term weight gains than those mothers who displayed no increase in dissatisfaction with their bodies after pregnancy. This association suggests either (a) that increased body image dissatisfaction predisposes mothers to gain more weight in association with pregnancy or (b) that mothers who gained more weight after pregnancy were more dissatisfied with their bodies. Bivariate correlation analyses showed that mothers who were more dissatisfied with their bodies postpartum, were also more likely to have reported an increase in energy intake after pregnancy. While it is impossible to determine the causal direction of these relations, previous analyses have demonstrated significantly higher levels of depression among women with increased body dissatisfaction after pregnancy. ${ }^{52}$ It might therefore be that the changes in body image that occur after pregnancy lead to depression and reduced self esteem, which in themselves are known risk factors for increased energy intake,,$^{53}$ particularly in women. ${ }^{54} 55$

After accounting for parental obesity and increased dissatisfaction with body image after pregnancy, a modest trend was observed for higher long term weight gains among women who felt they ate more postpartum than they did before they were pregnant (see table 6). Mothers who felt they had increased their energy intake after pregnancy had long term weight gains that were, on average, $2.9 \mathrm{~kg}$ greater than those of mothers who felt they had not increased their energy intake after pregnancy. This may be important because more than a fifth of the mothers in the sample reported increasing their energy intake after the birth of their child. These changes in food intake must play an important part in long term weight gain because more than $13 \%$ of the mothers who reported increasing their energy intake after pregnancy were newly classified as overweight or obese (BMI $>26.0$ $\mathrm{kg} / \mathrm{m}^{25}$ ) after pregnancy. This finding confirms Öhlin and Rössner's observation that weight retention at one year postpartum was greater among mothers who reported increasing their energy intake both during and after pregnancy. ${ }^{33}$

It has been suggested that mothers may be at increased risk of weight gain because they have greater access to food after their children are born, ${ }^{21}$ and tentative evidence to support this 
hypothesis came from a previous descriptive study $^{52}$ that suggested that mothers with increased access to food might be more vulnerable to postpartum weight gain. However, the ANCOVA models (see tables 5 and 6) showed no significant independent association between increased access to food and long term maternal weight gain. Changes in access to food that are independent of changes in energy intake are likely to simply reflect changes in the amount of time spent at home or in the preparation of food, and while the amount of time spent at home might provide a crude proxy for activity, a measure of self reported changes in activity had already been included in the ANCOVA model. If access to food had served as a proxy for time spent at home, it is perhaps not surprising that there was no independent association between a reduction in these measures of activity and long term maternal weight gain, and this finding is consistent with previous studies by Schauberger et al, ${ }^{31}$ Öhlin and Rössner ${ }^{33}$ and Walker. ${ }^{34}$ Although a crude association between reduced activity postpartum and increased weight gain is evident in an earlier study, ${ }^{52}$ this may have been the result of confounding with energy intake, because reported increase in food intake was significantly correlated with a reported decrease in activity (see table 4). Likewise, the predominantly sedentary lifestyles of most European and North American women ${ }^{56}$ might well explain the reduced importance of activity in maternal energy balance among these women. These results, and those of previous studies, ${ }^{31} 3334$ suggest that changes in energy intake rather than energy expenditure are more critical determinants of postpartum weight gain in women living in these settings.

Smoking is known to suppress appetite and has been shown to be associated with lower food intakes during pregnancy. ${ }^{57}$ Furthermore, quitting smoking has been linked to subsequent weight gain. ${ }^{59}$ In this study however, changes in smoking status had no significant independent effect on long term changes in maternal body weight. When the adjusted maternal weight gains for women of different smoking status are examined (see table 5), non-smokers, as expected, tended to gain more weight in association with their pregnancies (3.6 kg more on average) than those mothers who smoked continually throughout pregnancy and the postpartum period. Nevertheless, mothers who reported quitting or reducing their level of smoking during pregnancy did not have weight gains that were higher than those of their smoking or nonsmoking peers. While this might reflect the inherent inaccuracies of maternal reports of smoking behaviour, ${ }^{6162}$ the small numbers of mothers who reduced their level of smoking (n $=24)$ or started smoking $(\mathrm{n}=2)$ in this study may not have provided a representative view of how changes in smoking behaviour influence maternal weight gain.

As an established risk factor for long term weight gain ${ }^{23} 25-30$ it is surprising that there was no independent association between gestational weight gain and maternal obesity in this study. To some extent this might have been because of the minimal variation in gestational weight gains observed (95\% CI: 11.6, 14.2). Alternatively, it may have been the result of inherent inaccuracies in the maternal reports of gestational weight gain that were used to provide an estimate of weight gain during pregnancy. In the absence of comprehensive antenatal weight measurements, there was no alternative but to rely on these maternal reports of gestational weight gain. Nevertheless, to assess the accuracy of these, the medical records of all 74 mothers were re-examined to identify any with sufficient weight measurements to calculate gestational weight gain. When the recorded gestational weight gains of these eight mothers were compared with their self reported gestational weight gain, the correlation explained only two thirds of the variance in reported weight gain $\left(r^{2}=0.666 ; \mathrm{p}>0.05\right)$, which is probably insufficiently precise to identify the true importance of gestational weight gain to long term weight gains.

While the results of this study show that a heritable predisposition to gain weight together with changes in body image explain some of the changes in body weight associated with pregnancy, social support also seemed to be somehow related to the development of maternal body weight after pregnancy. Mothers with fewer supportive relationships tended to have higher long term weight gains than those with larger social networks $(p=0.093)$. As compensatory eating may be a more common phenomenon among mothers who feel isolated and lonely during the postpartum period, ${ }^{63}$ it has been suggested that weight loss after delivery might depend upon the amount of social support each mother receives. Although the association between social support and long term weight gain failed to reach significance (see table 6), the modest trend observed was independent of potential confounders and other risk factors for pregnancy related weight gain.

A number of methodological limitations might have influenced the findings of this study, and for this reason the associations observed between changes in lifestyle and long term maternal weight gain remain tentative. Firstly, information on prepregnancy eating habits and activity patterns were gathered retrospectively and may have been subject to recall bias. In particular, retrospective recall of certain behaviours might have introduced bias if mothers misreported these behaviours as post hoc justification for any weight gains they had experienced. However, by using data contained within the ANC Project database, it was possible to minimise the amount of information collected retrospectively. Secondly, the study design enabled the authors to describe associations between long term weight gain and the variables under test, but not to establish causality. Subsequent intervention studies would be necessary to establish the direction of these associations. Finally, the sample constitutes a relatively small group of women who were not entirely representative of the original ANC study cohort. However, the sample did not differ in those key anthropometric (booking weight) and reproduc- 
tive (parity) characteristics that are known to be associated with a differential risk of maternal obesity in women from south east England. ${ }^{23} 24$ For this reason, it is probable that the findings of this study reflect many of the ways in which preexisting factors and changes in lifestyle interact to influence long term weight gain among well nourished mothers in the United Kingdom.

The authors would like to thank all the mothers who took part in the study as well as the staff from the medical records departments at Guy's, St Thomas's, and Lewisham Hospitals. We are also grateful to Bridget Candy for her assistance with recruiting mothers into the study.

Funding: financial support was provided by the DevR fund of the University of Greenwich. The Antenatal Care Project was funded by the NHS Executive, South Thames.

Conflicts of interest: none.

1 British Nutrition Foundation. The nature and risks of obesity: Briefing paper-27. London: The British Nutrition Foundation, 1992:18.

2 Manson JE, Colditz GA, Stampfer MJ. Parity, ponderosity, and the paradox of a weight-preoccupied society. $7 A M A$ 1994;271:1788-90.

3 National Centre for Health Statistics. Plan and operation of the National Health and Nutrition Examination Survey, 1976-1980. Hyattsville, USA: DHSS Publication No. 1976-1980. Hyattsville, USA: DHSS Publication No.
[PHS] 81-1317, Vital and Health Statistics, series 1, no 15, [PHS] 81-1317.

4 Garrow JS. Obesity and related disorders. Edinburgh: Churchill Livingstone, 1988:329.

5 US Institute of Medicine. Nutrition during pregnancy. Washington DC: National Academy Press, 1990:468.

6 Perri MG, Nezu AM, Viegener BJ. Improving the long term management of obesity: Theory, research, and clinical guidelines. New York: John Wiley, 1992:9-14

7 Crowell, DT. Weight change in the postpartum period. A review of the literature. I Nurse Midwifery 1995;40:418-23.

8 Department of Health. The health of the nation: a strategy for health in England. London: HMSO, 1992:112.

9 Department of Health. Our healthier nation. A contract for health. London: HMSO, 1998:90.

10 Bradley PJ. Pregnancy as a cause of obesity. Int $\mathcal{F}$ Obes 1992; 16:935-6.

11 Cederlöf R, Kaij L. The effect of childbearing on body weight: a twin control study. Acta Psychiatr Scand Suppl weight: a twin

12 Heliövaara M, Aromaa A. Parity and obesity. 7 Epidemiol Community Health 1981:35:197-9.

13 Brown JE, Kaye SA, Folsom AR. Parity-related weigh change in women. Int $\mathcal{F}$ Obes 1992;16:627-31.

14 Stander HJ, Pastore JB. Weight changes during pregnancy and puerperium. Am F Obstet Gynecol 1940;39:928-37.

15 Waters EG. Weight studies in pregnancy. Am $\mathcal{F}$ Obstet Gynecol 1942;43:826-32.

16 Sheldon JH. Maternal obesity. Lancet 1949;ii:869-73.

17 Gurney R. The hereditary factor in obesity. Arch Intern Med 1936;57:557-61.

18 Greene JA. Clinical study of the etiology of obesity. Ann Intern Med 1939;12:1797-803.

19 Bray GA. Definition, measurement, and classification of the syndromes of obesity. Int $\mathcal{F}$ Obes 1978;2:99-112.

20 Johnston EM. Weight changes during pregnancy and the postpartum period. Progress in Food and Nutrition Science postpartum period.

21 Lederman SA. The effect of pregnancy weight gain on later obesity. Obstet Gynecol 1993;82:148-55.

22 Rössner S, Öhlin A. Pregnancy as a risk factor for obesity: Lessons from the Stockholm pregnancy and weight Lessons from the Stockholm pregnancy
development study. Obes Res 1995;3:267-75s.

23 Harris HE, Ellison GTH, Holliday $M$, et al. The impact of pregnancy on the long term weight gain of primiparous women in England. Int 7 Obes 1997a;21:747-55.

24 Harris HE, Ellison GTH, Holliday M. Is there an ( weight gain? Ann Hum Biol 1997b;24:507-19.

25 Greene GW, Smiciklas-Wright H, et al. Postpartum weight change: How much of the weight gained in pregnancy will be lost after delivery? Obstet Gynecol 1988;71:701-7.

26 Keppel KG, Taffel SM. Pregnancy-related weight gain and retention: Implications of the 1990 Institute of Medicine Guidelines. Am f Public Health 1993;83:1100-3.

27 Parker JD, Abrams BA. Differences in postpartum weight retention between black and white mothers. Obstet Gynecol 1993;81:768-74.

28 Boardley DJ, Sargent RG, Coker AL, et al. The relationship between diet, activity, and other factors, and postpartum between diet, activity, and other factors, and postpar
weight change by race. Obstet Gynecol 1995;86:834-8.

29 Scholl TO, Hediger ML, Schall JI, et al. Gestational weight gain, pregnancy outcome and postpartum weight retention. Obstet Gynecol 1995;86:423-7.

30 Harris HE, Ellison GTH, Holliday $M$, et al. Do the increased weight-gain recommendations for pregnancy predispose parous women to obesity? Proc Nutr Soc 1997c 56:154A.
31 Schauberger CW, Rooney BL, Brimer LM. Factors that influence weight loss in the puerperium. Obstet Gynecol 1992;79:424-9.

32 Stevens-Simon C, Roghmann KJ, McAnarney ER. Relationship of self-reported pre-pregnant weight and weight gain during pregnancy to maternal body habitus and age. $\mathcal{F}$ Am Diet Assoc 1992;92:85-6.

33 Öhlin A, Rössner S. Trends in eating patterns, physical activity and socio-demographic factors in relation to postpartum body weight development. Br f Nutr 1994;71:45770.

34 Walker LO. Predictors of weight gain at 6 and 18 months after childbirth: A pilot study. F Obstet Gynecol Neonatal Nurs 1996;25:39-48.

35 Sikorski, J, Wilson J, Clement S, et al. A randomised controlled trial comparing two schedules of antenatal visits: the antenatal care project. $B M \mathcal{F} 1996 ; 312: 546-53$.

36 Harris HE, Ellison GTH. Practical approaches for estimating prepregnant body weight. F Nurse Midwifery 1998;43: 97-101.

37 Harris HE, Ellison GTH. Does pregnancy predispose parous women to obesity?

38 Registrar General's classification of occupations. London:

39 Harris HE, Inayat Q. Developing semi-structured interview schedules for gathering psychosocial health data. Pilot results for a questionnaire on postnatal obesity. Nurse Researcher 1997;5:73-85.

40 Sørensen TIA, Stunkard AJ. Does obesity run in families because of genes? An adoption study using silhouettes as a measure of obesity. Acta Psychiatr Scand Suppl 1993;370: 67-72.

41 Abidin RR. Parenting Stress Index: professional manual. 3rd ed. Odessa, Florida: Psychological Assessment Resources, 1995.

42 Sarason BR, Shearin EN, Pierce GR, et al. Interrelationships of social support: measures: theoretical and practical implications. F Pers Soc Psychol 1987;52:813-32.

43 Sarason IG, Levine HM, Basham RB, et al. Assessing social support: the Social Support Questionnaire. 7 Pers Soc Psychol 1983;44:127-39.

44 Weinman J, Wright S, Johnston M. Social support: measures in health psychology, a user's portfolio. Windsor: NFERNELSON Publishing Company, 1995:7-8.

45 Cox JL, Holden JM, Sagovsky R. Detection of postnatal depression: development of the 10-item Edinburgh Postnatal Depression Scale. Br F Psychiatry 1987;150:782-6.

46 Thorpe K. A study of the use of the Edinburgh Postnatal Depression Scale with parent groups outside the postpar-
tum period. Fournal of Reproductive Infant Psychology 1993; 11:119-26.

47 Garner DM, Olmsted MP, Polivy J. Development and validation of a multidimensional eating disorder inventory for anorexia nervosa and bulimia. Int $\mathcal{F}$ Eat Disord 1983;2:1534 .

48 Van Strien T, Frijters JER, Bergers GPA, et al. The Dutch Eating Behaviour Questionnaire (DEBQ) for assessment of restrained, emotional and external eating behaviour. Int $\mathcal{f}$ Eat Disord 1986;5:295-315.

49 Stunkard AJ, Sørensen TIA, Hanis C, et al. An adoption study of human obesity. N Engl F Med 1986;314:193-8.

50 Sørensen TIA, Price RA, Stunkard AJ, et al. Genetics of obesity in adult adoptees and their biological siblings. BMF 1989;298:87-90

51 Sørensen TIA, Holst C, Stunkard AJ, et al. Correlations of body mass index of adult adoptees and their biological and adoptive relatives. Int $\mathcal{F}$ Obes 1992;16:227-36.

52 Harris HE. The influence of pregnancy on long-term changes in maternal body weight. [PhD thesis]. London: University of Greenwich, 1997:136-60.

53 DiPietro L, Anda RF, Williamson DF, et al. Depressive symptoms and weight change in a National cohort of adults. Int $\mathcal{F}$ Obes 1992;16:745-53.

54 Pine CJ. Anxiety and eating behaviour in obese and nonobese American Indians and White Americans. F Person Soc Psychol 1985;49:774-80.

55 Grunberg NE, Straub RO. The role of gender and taste class in the effects of stress on eating. Health Psychol 1992;11:97100.

56 Raaij JMA van, Schonk CM, Vermaat-Miedema SH, et al. Energy cost of physical activity throughout pregnancy and the first year postpartum in Dutch women with sedentary lifestyles. Am f Clin Nutr 1990;52:234-9.

57 Haste FM, Brooke OG, Anderson HR, et al. Nutrient ntakes during pregnancy: observations on the influence of smoking and social class. Am f Clin Nutr 1990;51:29-36.

58 Haste FM, Brooke OG, Anderson HR, et al. The effect of nutritional intake on outcome of pregnancy in smokers and non-smokers. Brf N Nutr 1991;65:347-54.

59 Williamson DF, Madans J, Anda RF, et al. Smoking cessation and severity of weight gain in a national cohort. $N$ Engl F Med 1991;324:739-45.

60 Gordon T, Kannel WB, Dawber TR, et al. Changes associated with quitting cigarette smoking: The Framingham Study. Am Heart $\mathcal{~}$ 1975;90:322-8.

61 Burman JF. The misinformation era: The fall of the medical record. Ann Intern Med 1989;110:482-4.

62 Kokotailo PK, Adger H, Duggan AK, et al. Cigarette, alcohol and other drug use by school-age pregnant adolescents: Prevalence, detection, and associated risk factors. Pediatrics 1992;90:328-34.

63 Gillen RS. Does pregnancy cause obesity? [Letter]. Med $\mathcal{F}$ Aust 1990;152:112. 